\title{
Regime crystallization in syndiotactic polypropylenes: re-evaluation of the literature data
}

\author{
P. Supaphol, J.E. Spruiell* \\ Center for Materials Processing, Department of Materials Science and Engineering, University of Tennessee, 434 Dougherty Engineering Building, Knoxville, \\ TN 37996-2200, USA
}

Received 11 March 1998; received in revised form 20 March 1999; accepted 25 March 1999

\begin{abstract}
The Lauritzen and Hoffman secondary nucleation theory was applied to linear growth rate data of syndiotactic polypropylene taken from the literature. Observation of the distinctive upward change of slope in plots of log $G+U^{*} / 2.303 R\left(T_{\mathrm{c}}-T_{\infty}\right)$ versus $1 / 2.303 T_{\mathrm{c}}(\Delta T) f$ suggested the regime II $\rightarrow$ III transition at the crystallization temperature of $110^{\circ} \mathrm{C}$. Based on the input parameters judged to be the most accurate, the ratios of $K_{\mathrm{g}, \mathrm{III}} / K_{\mathrm{g}, \mathrm{II}}$ were found to range from 1.7 to 2.2. Regardless of the crystal structure, if the growth is assumed to occur on the $b c$ plane, the lateral surface free energy, $\sigma=11.3 \mathrm{erg} \mathrm{cm}^{-2}$ and the fold surface free energy $\sigma_{\mathrm{e}}=63.7 \pm 7.1 \mathrm{erg} \mathrm{cm}^{-2}$ were found. The latter leads to the average work of chain folding of $\bar{q}=7.4 \pm 0.8 \mathrm{kcal} \mathrm{mol}^{-1}$. If the growth is assumed to occur on the $a c$ plane, the fold surface free energy is found to be $\sigma_{\mathrm{e}}=82.4 \pm 9.1 \mathrm{erg} \mathrm{cm}^{-2}$, while the lateral surface free energy is the same as previously noted. In this case, the work of chain folding of $\bar{q}=9.6 \pm 1.1 \mathrm{kcal} \mathrm{mol}^{-1}$ is found. These values are applicable to both regimes II and III. A detailed evaluation of the effects of changes in input parameters was also carried out. (C) 1999 Elsevier Science Ltd. All rights reserved.
\end{abstract}

Keywords: Secondary nucleation kinetics; Crystal growth kinetics; Regime crystallization

\section{Introduction}

The polymer crystal growth or secondary nucleation kinetics theory introduced by Lauritzen and Hoffman [13] (i.e. the LH secondary nucleation theory) has been developed and revised repeatedly in subsequent publications essentially by Hoffman and his co-workers [4-10]. The theory suggests that polymers crystallize in three different regimes, as opposed to the classical theory of secondary nucleation in which the deposition of a single nucleus on a growth face is followed by a rapid lateral spreading process. The simplest way of understanding regime crystallization is to envisage the growth process as being composed of two different processes. The first is the deposition of the secondary nucleus on the growth face, while the second is the lateral spreading of polymer chains or segments of the chains across the growth face. Regime I is very similar to the notion of the classical theory in which the lateral speading rate is much greater than that of the surface nucleation rate. Regime II is observed when the rates of the two processes are comparable, and regime III

\footnotetext{
* Corresponding author. Tel.: +1-423-974-5336; fax: +1-423-974-4115.

E-mail addresses: ps@govolsfan.com (P. Supaphol); spruiell@utk.edu (J.E. Spruiell)
}

occurs when the rate of secondary nucleation is greater than that of the lateral spreading.

Fundamentally, a regime transition is observed as a break in the growth rate data with respect to the crystallization temperature or, to be exact, the degree of undercooling. In the highest temperature regime, where regime I is observed, the growth rate $G$ is directly proportional to the secondary nucleation rate $i$ (i.e. $G \propto i$ ). At moderate undercoolings, where regime II is observed, multiple surface nucleation occurs on a growth face, resulting in a growth rate that depends on the square root of the secondary nucleation rate, i.e. $G \propto \sqrt{ } i$. As the undercooling is further decreased, multiple surface nucleation becomes so prolific that the niche separation approaches the size of a single stem, and the dependence of the growth rate and the surface nucleation rate switches back to that of regime I (i.e. $G \propto i)$ ). Due to the relationship of the growth rate with the secondary nucleation rate in all three regimes, it is obvious that one should observe a downward break in the growth rate data at the point where the regime I $\rightarrow$ II transition occurs, and an upward break where regime $\mathrm{II} \rightarrow$ III transition occurs.

Based on the growth rate studies in various laboratories, the presence of a regime $\mathrm{I} \rightarrow \mathrm{II}$ transition has been observed in polyethylene [4], and poly(L-lactic acid) [11]. Regime II $\rightarrow$ III transitions have been observed in polyethylene [6], 
isotactic polypropylene (i-PP) [7], and poly(oxymethylene) [12]. The appearance of all of the three regimes was first observed in the studies of fractions of cis-polyisoprene by Phillips and Vatansever [13]. Recently, regime crystallization kinetics in polyethylene was discussed in a great deal of detail, both theoretically and experimentally by Hoffman and Miller [10]. In the case where the growth rate data is not available or is too time-consuming to obtain, the overall crystallization rate (denoted by $t_{\theta}^{-1}$, the reciprocal value of the time taken from the onset of the crystallization process to reach a certain value of relative crystallinity $\theta$ ), obtained directly from the bulk crystallization, can also be used to observe regime crystallization in polymers. This type of study has been applied in various polymer systems, such as polyethylene [14,15], and crosslinked polyethylene [16].

Miller and Seeley $[17,18]$ were the first group to conduct spherulitic growth rate measurements on syndiotactic polypropylene (s-PP). They studied a sample having a racemic dyad concentration of $71.7 \%$ over the crystallization temperature range of $97.4-137.3^{\circ} \mathrm{C}$. By assuming that the s-PP crystallized in regime II, and using the values of the glass transition temperature $T_{\mathrm{g}}$, the equilibrium melting temperature $T_{\mathrm{m}}^{0}$, and the enthalpy of fusion $\Delta H_{\mathrm{f}}^{0}$, to be $0^{\circ} \mathrm{C}, 161^{\circ} \mathrm{C}$ and $3.14 \mathrm{~kJ} \mathrm{~mol}^{-1}$, respectively, the lateral and fold surface free energies, $\sigma$ and $\sigma_{\mathrm{e}}$ were estimated to be 4.4 $\left(1 \mathrm{erg} \mathrm{cm}{ }^{-2}=1 \mathrm{~mJ} \mathrm{~m}^{-2}\right.$ ) and $58 \mathrm{erg} \mathrm{cm}^{-2}$, respectively. They also calculated the average work of chain folding $\bar{q}$ to be $6.8 \mathrm{kcal} \mathrm{mol}^{-1}$. Later in 1984, Clark and Hoffman [7] re-examined the growth rate data published by Miller and Seeley [17,18], and estimated $\sigma_{\mathrm{e}}$ to be $49.9 \mathrm{erg} \mathrm{cm}^{-2}$ and $\bar{q}$ to be $5.8 \mathrm{kcal} \mathrm{mol}^{-1}$, using the same value of $T_{\mathrm{m}}^{0}$. They also suggested that a regime II $\rightarrow$ III transition should occur somewhere in the crystallization temperature range of $110-115^{\circ} \mathrm{C}$, or at the undercooling $\Delta T$ of around $50^{\circ} \mathrm{C}$. It was not clear, however, how they came up with these estimates.

In 1994, Rodriguez-Arnold and her co-workers [19] performed a spherulitic growth rate measurement on two fractions of s-PP samples with racemic pentads [\% rrrr] in the range of $86-87 \%$. They found a discontinuity in the growth rate data at the crystallization temperature, $T_{\mathrm{c}}$, of $110^{\circ} \mathrm{C}$. As $T_{\mathrm{m}}^{0}$ of these two fractions were estimated to be $160^{\circ} \mathrm{C}$, this results in the regime $\mathrm{II} \rightarrow \mathrm{III}$ transition at the undercooling of $50^{\circ} \mathrm{C}$, similar to the value estimated by Clark and Hoffman [7]. Based on their earlier value of $\Delta H_{\mathrm{f}}^{0}$ for $100 \%$ crystallinity of $8.0 \mathrm{~kJ} \mathrm{~mol}^{-1}$ [20], and $T_{\mathrm{g}}$ of $0^{\circ} \mathrm{C}$ [17], they estimated that $\sigma$ is approximately $11.2 \mathrm{erg} \mathrm{cm}^{-2}, \quad \sigma_{\mathrm{e}}$ being in the range of $42.2-$ $47.7 \mathrm{erg} \mathrm{cm}^{-2}$, and $\bar{q}$ being between 4.9 and $5.6 \mathrm{kcal}$ $\mathrm{mol}^{-1}[19,21]$. Recently, we [22] also performed a spherulitic growth rate measurement on a s-PP sample of $77.1 \%$ syndiotacticity (racemic pentads) over the temperature range of $45-125^{\circ} \mathrm{C}$. Our result also confirmed that the regime $\mathrm{II} \rightarrow \mathrm{III}$ transition in s-PP occurs at $T_{\mathrm{c}}=110^{\circ} \mathrm{C}$. We did not, however, calculate the parameters characteristic of the growth theory.
It is known that the parameters characteristic of the growth theory (e.g. $\sigma, \sigma_{\mathrm{e}}$ and $\bar{q}$ ) are very sensitive to the input parameters used to calculate them (e.g. $T_{\mathrm{g}}, T_{\mathrm{m}}^{0}$ and $\left.\Delta H_{\mathrm{f}}^{0}\right)$. Comparison of these growth parameters obtained from different authors may lead to an ambiguous conclusion, as they often used different input parameters. In this manuscript, we re-analyzed these published spherulitic growth rate data $[17,18,22],{ }^{1}$ and re-calculated all the parameters characteristic of the growth theory using the same input parameters. The sensitivity of crystal growth parameters (e.g. $\sigma, \sigma_{\mathrm{e}}$ and $\bar{q}$ ) to changes in the input parameters (e.g. $T_{\mathrm{g}}, T_{\mathrm{m}}^{0}$ and $\Delta H_{\mathrm{f}}^{0}$ ) was also evaluated.

\section{Theoretical background}

In the context of the LH secondary nucleation theory [110 ], the linear growth rate $G$ of a crystalline aggregate (e.g. spherulite or axialite) for each regime is dependent on the degree of undercooling, $\Delta T$, and is defined by the following equation:

$G=G_{0} \exp \left(-\frac{U^{*}}{R\left(T_{\mathrm{c}}-T_{\infty}\right)}-\frac{K_{\mathrm{g}}}{T_{\mathrm{c}}(\Delta T) f}\right)$,

where $G_{0}$ is a pre-exponential term which is not strongly dependent on temperature, $U^{*}$ is the activation energy for the transportation of segments of molecules across the melt/ solid surface boundary and is usually given by a universal value of $1500 \mathrm{cal} \mathrm{mol}^{-1}, T_{\mathrm{c}}$ is the crystallization temperature, $T_{\infty}$ is the temperature where the molecular motion ceases (i.e. $T_{\infty}=T_{\mathrm{g}}-30$ ), $\mathrm{R}$ is the universal gas constant, $\Delta T$ is the degree of undercooling (i.e. $\Delta T=T_{\mathrm{m}}^{0}-T_{\mathrm{c}}$ ), and $f$ is a factor used to correct for the temperature dependence of the heat of fusion (i.e. $\left.f=2 T_{\mathrm{c}} /\left(T_{\mathrm{c}}+T_{\mathrm{m}}^{0}\right)\right)$ and $K_{\mathrm{g}}$ is the nucleation exponent, and is defined as:

$K_{\mathrm{g}}=\frac{\xi b_{0} \sigma \sigma_{\mathrm{e}} T_{\mathrm{m}}^{0}}{k \Delta H_{\mathrm{f}}^{0}}$

where $\xi$ equals 2 for regime II and 4 for regimes I and III, $b_{0}$ denotes the crystal layer thickness along the growth direction, $\sigma$ and $\sigma_{\mathrm{e}}$ are the lateral and fold surface free energy, respectively, $T_{\mathrm{m}}^{0}$ is the equilibrium melting temperature, $\mathrm{k}$ is the Boltzmann's constant, and $\Delta H_{\mathrm{f}}^{0}$ is the equilibrium heat of fusion.

\footnotetext{
${ }^{1}$ As Rodriguez-Arnold et al. did not publish their growth rate data of the two studied s-PP fractions (labeled as s-PP $(76.8 \mathrm{k})$ and s-PP $(132.0 \mathrm{k}$ ) in Ref. [19] or s-PP(8) and s-PP(9) in Ref. [20]) in their original publication [19] and only partial data are available in Ref. [21], we obtained their data by back-calculation (using the same parameters as theirs: $T_{\mathrm{m}}^{0}=160^{\circ} \mathrm{C}$, $T_{\mathrm{g}}=0^{\circ} \mathrm{C}$, and $\Delta H_{\mathrm{f}}^{0}=8.0 \mathrm{~kJ} \mathrm{~mol}^{-1}$ ) from their results shown as Fig. 4 in Ref. [19] or Fig. 6.4 in Ref. [21]. In addition, we also back-calculated (using $T_{\mathrm{m}}^{0}=160^{\circ} \mathrm{C}$ ) the growth rate data from their results shown as Fig. 3 in Ref. [19] or Fig. 6.3 in Ref. [21]. These regenerated data were averaged, and later compared with their original data partially listed in Table 6.1 in Ref. [21].
} 
Referring to Eq. (1), the first exponential term, $\exp \left(-U^{*} / R\left(T_{\mathrm{c}}-T_{\infty}\right)\right)$, corresponds to the diffusion of polymer molecules or segments of them from the equilibrium melt onto the growth face. The second exponential term, $\exp \left(-K_{\mathrm{g}} / T_{\mathrm{c}}(\Delta T) f\right)$, relates to the formation of the critical nucleus on the growth face. Obviously, this term relates directly to the secondary nucleation rate, $i$. Intuitively, from the competing contributions of the transport and nucleation terms, one expects that there should be a maximum in the growth rate data at a temperature somewhere between the glass transition temperature and the equilibrium melting temperature, when plotted as a function of the crystallization temperature. Indeed, maxima in the growth rate data as a function of crystallization temperature are usually observed at $(0.7-0.8) T_{\mathrm{m}}^{0}[7]$.

As mentioned earlier, in each regime the linear growth rate, $G$, relates directly to the secondary nucleation rate, $i$ : $G \propto i^{n}$, where $n$ equals 1 in regimes I and III, and 0.5 in regime II. As the second exponential term in Eq. (1) corresponds directly to the secondary nucleation rate, observation of the relationship between $G$ and $i$ can be examined by rearranging the logarithmic product of Eq. (1), which results in the equation:

$\log G+\frac{U^{*}}{2.303 R\left(T_{\mathrm{c}}-T_{\infty}\right)}=\log G_{0}-\frac{K_{\mathrm{g}}}{2.303 T_{\mathrm{c}}(\Delta T) f}$.

In practice, the test of regimes can be done through the plot of $\log G+U^{*} / 2.303 R\left(T_{\mathrm{c}}-T_{\infty}\right)$ versus $1 / 2.303 T_{\mathrm{c}}(\Delta T) f$ (i.e. hereafter the LH plot). This type of plot factors out the contribution of the transport term to the growth rate, and the slope equals the negative value of the nucleation exponent (i.e. slope $=-K_{\mathrm{g}}$ ). According to Eq. (3), regime I $\rightarrow$ II transition is evident when a downward change in slope is observed, whereas it is an upward change in slope that is observed in the transition from regime II to regime III.

Once the nucleation exponent values, $K_{\mathrm{g}}$, have been determined, other parameters characteristic of crystal growth can be estimated. First, $\sigma \sigma_{\mathrm{e}}$ can be calculated from Eq. (2), provided the other parameters are known. By referring to Eq. (2), the only unknown parameter is the layer thickness $b_{0}$, which can be estimated from the unit cell parameters. It is, therefore, imperative to know into what type of crystallographic form the s-PP samples crystallize in the temperature range of interest. Based on our preliminary WAXD results [23], it is obvious that all of the s-PP samples crystallize mainly in the high temperature orthorhombic form II (Cell II) as determined by Lotz and coworkers [24], especially when $60<T_{\mathrm{c}}<110^{\circ} \mathrm{C}$. The unit cell of this orthorhombic modification has space group symmetry Pca $2{ }_{1}$, with the axis dimensions: $a=14.50 \AA, b=5.60 \AA$, and $c=7.40 \AA$. This structure is characterized by the existence of helices of opposite hands with chain axes in $(0,0, z)$ and $(1 / 2,0, z)$. However, when $T_{\mathrm{c}}>110^{\circ} \mathrm{C}$, it is a combination of the high temperature orthorhombic form II (Cell II) [24] and form III (Cell III) [24,25] which exists after 
Table 2

Linear spherulitic growth rate data for syndiotactic polypropylene samples used in the reference literature

\begin{tabular}{|c|c|c|c|c|c|c|c|c|}
\hline \multirow[t]{2}{*}{ Sample label } & \multicolumn{2}{|l|}{$6 \mathrm{H}$} & \multicolumn{2}{|l|}{ s-PP(8) } & \multicolumn{2}{|l|}{ s-PP(9) } & \multicolumn{2}{|l|}{ s-PP\#1 } \\
\hline & $T_{\mathrm{c}}\left({ }^{\circ} \mathrm{C}\right)$ & $G\left(\mu \mathrm{m} \min ^{-1}\right)$ & $T_{\mathrm{c}}\left({ }^{\circ} \mathrm{C}\right)$ & $G\left(\mu \mathrm{m} \min ^{-1}\right)$ & $T_{\mathrm{c}}\left({ }^{\circ} \mathrm{C}\right)$ & $G\left(\mu \mathrm{m} \min ^{-1}\right)$ & $T_{\mathrm{c}}\left({ }^{\circ} \mathrm{C}\right)$ & $G\left(\mu \mathrm{m} \min ^{-1}\right)$ \\
\hline & 97.4 & 7.32 & 101.0 & 9.12 & 100.0 & 5.82 & 45.0 & 1.55 \\
\hline & 101.4 & 7.42 & 102.0 & 7.74 & 101.0 & 4.79 & 50.0 & 2.15 \\
\hline & 104.4 & 4.92 & 103.0 & 6.74 & 102.0 & 4.18 & 55.0 & 3.32 \\
\hline & 105.4 & 4.28 & 104.0 & 5.99 & 103.0 & 3.48 & 60.0 & 3.75 \\
\hline & 109.4 & 4.22 & 105.0 & 5.18 & 104.0 & 3.11 & 65.0 & 4.29 \\
\hline & 113.4 & 1.83 & 106.0 & 4.62 & 105.0 & 2.68 & 70.0 & 4.24 \\
\hline & 117.4 & 1.61 & 107.0 & 3.95 & 106.0 & 2.18 & 75.0 & 4.17 \\
\hline & 121.4 & 0.94 & 108.0 & 3.10 & 108.0 & 1.69 & 80.0 & 3.80 \\
\hline & 125.4 & 0.44 & 109.0 & 2.67 & 110.0 & 1.16 & 85.0 & 2.78 \\
\hline & 129.4 & 0.27 & 111.0 & 1.84 & 111.0 & 1.07 & 90.0 & 1.92 \\
\hline & 133.4 & 0.10 & 113.0 & 1.41 & 112.0 & 0.94 & 95.0 & 1.38 \\
\hline & 137.3 & 0.02 & 116.0 & 1.03 & 113.0 & 0.80 & 100.0 & 0.72 \\
\hline & & & & & 114.0 & 0.72 & 105.0 & 0.48 \\
\hline & & & & & 115.0 & 0.63 & 110.0 & 0.21 \\
\hline & & & & & 116.0 & 0.55 & 115.0 & 0.11 \\
\hline & & & & & 118.0 & 0.42 & 120.0 & 0.08 \\
\hline & & & & & & & 125.0 & 0.04 \\
\hline Data source & \multicolumn{2}{|c|}{ Miller and Seeley $[17,18]$} & \multicolumn{2}{|c|}{ Rodriguez-Arnold et al. [19,21] } & \multicolumn{2}{|c|}{ Rodriguez-Arnold et al. $[19,21]$} & \multicolumn{2}{|c|}{ Supaphol et al. [22] } \\
\hline
\end{tabular}

crystallization. Cell III is characterized by full antichirality along both the $a$ and $b$ axes, with the unit cell having a doubled $b$ axis $(b=11.2 \AA)$, and space group symmetry Ibca.

By assuming that (010) or (200) is the growth plane for Cell II (or (020) or (200) for Cell III) (i.e. the $a c$ growth plane or the $b c$ growth plane, respectively), we are thus able to estimate the molecular width $a_{0}$ and the layer thickness $b_{0}$. At this point, we are able to calculate the lateral and fold surface free energy, $\sigma$ and $\sigma_{\text {e }}$, separately. However, we have to first estimate $\sigma$, based on the modified Thomas-Staveley

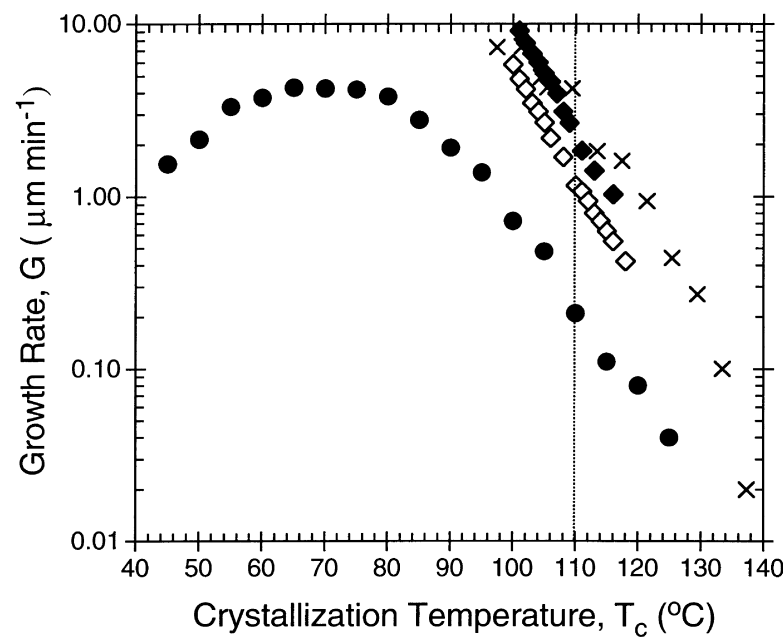

Fig. 1. Spherulitic growth rates of syndiotactic polypropylene as a function of crystallization temperatures: $(\times)$ data of Miller and Seeley (sample $6 \mathrm{H}$ ) $[17,18]$; $(\bullet)$ data of Rodriguez-Arnold et al. (sample s-PP $(8)$ ) [19,21] (see footnote 1); $(\diamond)$ data of Rodriguez-Arnold et al. (sample s-PP(9)) [19,21] (see footnote 1); (๑) data of Supaphol et al. (sample s-PP\#1) [22]. equation [26]:

$\sigma=\alpha \Delta H_{\mathrm{f}}^{0} \sqrt{a_{0} b_{0}}$,

where $a_{0} b_{0}$ is the cross-sectional area of one chain molecule, and $\alpha$ is a universal parameter related to the chemical nature of the polymer, and often taken to be 0.1 . It is worth noting that the choice of $\alpha=0.1$ may be justified for the case of s-PP based on the fact that the $\sigma_{\mathrm{e}}$ values estimated by Rodriguez-Arnold et al. [19-21] based on the modified ThomasStaveley method (using $\alpha=0.1$ ) and the Gibbs-Thomson method are comparable within an experimental error. Once $\sigma$ is known, the fold surface free energy $\sigma_{\mathrm{e}}$ can be calculated from $\sigma \sigma_{\mathrm{e}} / \sigma$. Finally, the average work of chain folding $\bar{q}$ which is defined as

$\bar{q}=2 a_{0} b_{0} \sigma_{\mathrm{e}}$

can also be calculated.

\section{Materials, linear growth rate and input data}

Four sets of linear growth rate data for syndiotactic polypropylene spherulites were taken from the literature [17-22] (see footnote 1) for re-analysis in this paper. The material characterization data for s-PP samples examined are summarized in Table 1. The spherulitic growth rate data for these samples are listed in Table 2. It is noteworthy that the listing of these data is for future reference only.

Fig. 1 represents the relationship between the spherulitic growth rate and the crystallization temperature for all of the $\mathrm{s}$-PP samples examined. It is evident that the growth rate for s-PP\#1 exhibits the typical bell-shaped dependence with the temperature, and the maximum in the growth rate data 
Table 3

Input parameters for calculation of crystal growth parameters

\begin{tabular}{|c|c|c|}
\hline Parameter & Value & Remarks \\
\hline Heat of fusion, $\Delta H_{\mathrm{f}}^{0}$ & $1.77 \times 10^{9} \mathrm{erg} \mathrm{cm}^{-3}$ & Refs. [19-21] \\
\hline Glass transition temperature, $T_{\mathrm{g}}$ & $-6.1^{\circ} \mathrm{C}$ or $267.0 \mathrm{~K}$ & Ref. [27] \\
\hline Equilibrium melting temperature, $\left(T_{\mathrm{m}}^{0}\right)_{100 \%}$ & $168.7^{\circ} \mathrm{C}$ or $441.8 \mathrm{~K}$ & Ref. [27] \\
\hline Boltzmann's constant, $k$ & $1.380 \times 10^{-16} \mathrm{erg} \mathrm{mol}^{-1} \mathrm{~K}^{-1}$ & \\
\hline \multicolumn{3}{|c|}{ For (010) growth plane (Cell II), or (020) growth plane (Cell III) } \\
\hline Molecular width, $a_{0}$ & $7.25 \times 10^{-8} \mathrm{~cm}$ & Estimated from Refs. [24,25] \\
\hline Layer thickness, $b_{0}$ & $5.60 \times 10^{-8} \mathrm{~cm}$ & Estimated from Refs. [24,25] \\
\hline Cross-sectional area of chain, $a_{0} b_{0}$ & $4.06 \times 10^{-15} \mathrm{~cm}^{2}$ & Estimated from Refs. [24,25] \\
\hline Lateral surface free energy, $\sigma$ & $11.3 \mathrm{erg} \mathrm{cm}^{-2}$ & From $\sigma=0.1 \Delta H_{\mathrm{f}}^{0}\left(a_{0} b_{0}\right)^{0.5}$ \\
\hline \multicolumn{3}{|c|}{ For (200) growth plane (either Cell II or Cell III) } \\
\hline Molecular width, $a_{0}$ & $5.60 \times 10^{-8} \mathrm{~cm}$ & Estimated from Refs. [24,25] \\
\hline Layer thickness, $b_{0}$ & $7.25 \times 10^{-8} \mathrm{~cm}$ & Estimated from Refs. [24,25] \\
\hline Cross-sectional area of chain, $a_{0} b_{0}$ & $4.06 \times 10^{-15} \mathrm{~cm}^{2}$ & Estimated from Refs. [24,25] \\
\hline Lateral surface free energy, $\sigma$ & $11.3 \mathrm{erg} \mathrm{cm}^{-2}$ & From $\sigma=0.1 \Delta H_{\mathrm{f}}^{0}\left(a_{0} b_{0}\right)^{0.5}$ \\
\hline
\end{tabular}

occurs at $T_{\mathrm{c}} \approx 70^{\circ} \mathrm{C}$. The growth rate data for $6 \mathrm{H}$, s-PP( $(8)$ and s-PP(9) samples are clearly in the high temperature region (low degree of undercooling), where the secondary nucleation is the rate determining process. From the figure, it is apparent that the rate of crystallization falls in the following order: s-PP $(8)>\mathrm{s}-\mathrm{PP}(9)>\mathrm{s}-\mathrm{PP} \# 1$. That s-PP(8) crystallizes faster than s-PP(9) appears to be due to the fact that the average molecular weight for s-PP(8) is much lower than that of s-PP(9) when other parameters are comparable. On the contrary, it may be the broader molecular weight distribution or the lower degree of syndiotacticity (racemic pentads [\% rrrr]) that accounts for the slowest crystallization rate observed in s-PP\#1. It is noteworthy that the

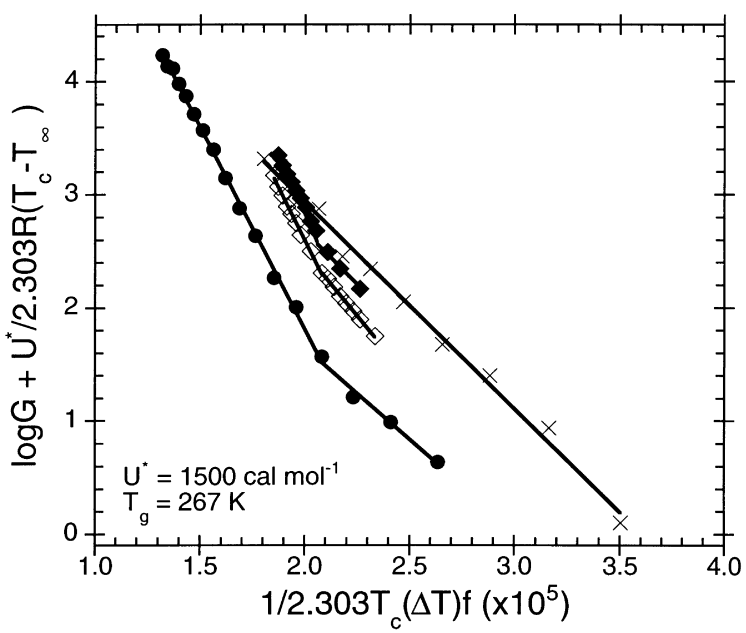

Fig. 2. Analysis of the spherulitic growth rates of syndiotactic polypropylene as a function of crystallization temperatures based on the Lauritzen and Hoffman secondary nucleation theory for the case $U^{*}=1500 \mathrm{cal} \mathrm{mol}^{-1}$, $T_{\infty}=T_{\mathrm{g}}-30=237.0 \mathrm{~K}$, and $\left(T_{\mathrm{m}}^{0}\right)_{100 \%}=441.8 \mathrm{~K}:(\times)$ data of Miller and Seeley (sample 6H) [17,18]; ( ) data of Rodriguez-Arnold et al. (sample s-PP(8)) [19,21] (see footnote 1); $(\diamond)$ data of Rodriguez-Arnold et al. (sample s-PP(9)) [19,21] (see footnote 1); () data of Supaphol et al. (sample s-PP\#1) [22] crystallization rate of $6 \mathrm{H}$ is not discussed here, as the WAXD scan of $6 \mathrm{H}$ sample (cf. Fig. 12 in Ref. [18]) shows peaks that are characteristic of i-PP. This can only be construed that the isotactic segments also take part in the crystallization process in $6 \mathrm{H}$ sample, as its racemic dyad content is only $72 \%$.

The input parameters used in this analysis for the calculation of crystal growth parameters were selected after careful evaluation of available data in the literature and are listed in Table 3. The most questionable literature data are the values of equilibrium melting temperature, $T_{\mathrm{m}}^{0}$, and the enthapy of fusion, $\Delta H_{\mathrm{f}}^{0}$, which are strongly dependent on the degree of syndiotacticity. The melting temperature used in this paper will be the estimated value (please see Ref. [27] for more details) for a s-PP sample exhibiting $100 \%$ syndiotacticity (denoted as $\left.\left(T_{\mathrm{m}}^{0}\right)_{100 \%}\right)$, which is $168.7^{\circ} \mathrm{C}(441.8 \mathrm{~K})$. The value of $\Delta H_{\mathrm{f}}^{0}$ is taken as the published value by Rodriguez-Arnold and her coworkers [19-21], which is $8.0 \mathrm{~kJ} \mathrm{~mol}^{-1}$ (i.e. $1.77 \times 10^{9} \mathrm{erg} \mathrm{cm}^{-3}$ ). Table 3 summarizes the values for enthalpy of fusion [19-21], glass transition temperature [27], equilibrium melting temperature for a $100 \%$ syndiotactic sample [27], and unit cell parameters $[24,25]$. Based on these input parameters, the lateral surface free energy $\sigma$ can be first estimated from Eq. (4) and was found to be $11.3 \mathrm{erg} \mathrm{cm}^{-2}$.

\section{Analysis and discussion of literature data}

\subsection{Determination of crystal growth parameters}

The s-PP growth rate data of Rodriguez-Arnold et al. [19,21] and Supaphol et al. [22] are available in a wide enough temperature range to exhibit the regime II $\rightarrow$ III transition, as evidenced by observation of a change in slope in each of the data sets for s-PP(8), s-PP(9) and s-PP\#1 samples shown in Fig. 2. The input parameters used in the plot are $U^{*}=1500 \mathrm{cal} \mathrm{mol}^{-1}, T_{\infty}=T_{\mathrm{g}}-30=237.0 \mathrm{~K}$ [27], and $\left(T_{\mathrm{m}}^{0}\right)_{100 \%}=441.8 \mathrm{~K}$ [27]. Even though the growth 


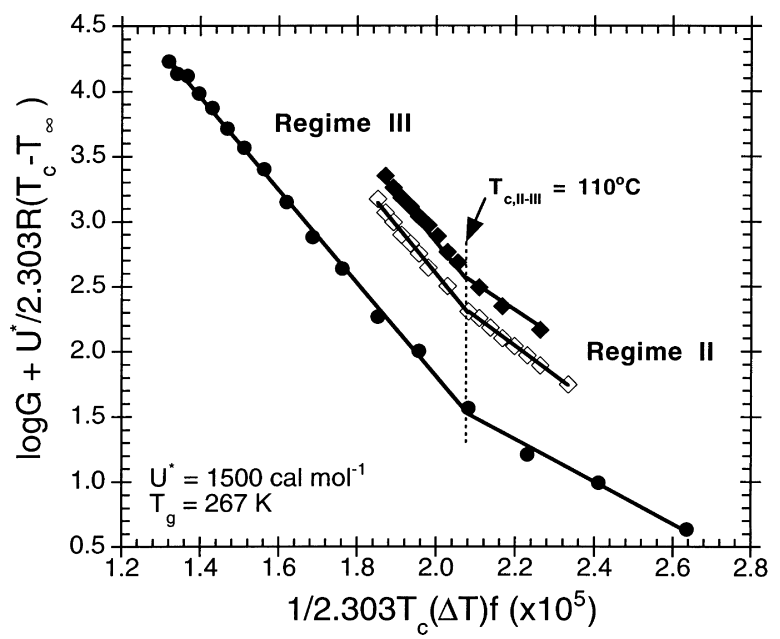

Fig. 3. The same plot as Fig. 2 but without the data of Miller and Seeley $(6 \mathrm{H}$ sample) $[17,18]$. The regime II $\rightarrow$ III transition is clearly distinguishable in all three sets of data, and corresponds to the crystallization temperature of $110^{\circ} \mathrm{C}$.

rate data of Miller and Seeley $[17,18]$ does not exhibit any discontinuity in the slope, Clark and Hoffman [7] suggested that these data are in regime II and can be analyzed accordingly.

With the absence of the $6 \mathrm{H}$ data, the regime $\mathrm{II} \rightarrow \mathrm{III}$ transition can be graphically distinguished in the data set for s-PP(8), s-PP(9) and s-PP\#1 samples, as illustrated in Fig. 3. This transition corresponds to the crystallization temperature of $110^{\circ} \mathrm{C}$, which is in very good agreement with the predicted value by Clark and Hoffman [7]. As mentioned previously, for each data set the nucleation exponent $K_{\mathrm{g}}$ for either regime II or III can be extracted directly from the slope of the plot (i.e. $K_{\mathrm{g}}=-$ slope). It is worth noting that the correlation coefficients $r^{2}$ of the straight lines fitting the bulk of the data are 0.984 or better. In addition, $G_{0}$ corresponding to either regime II or regime III can also be extracted from the $y$-interception of the plot (i.e. $\left.G_{0}=10^{\text {(y-intercept value) }}\right)$. Once $K_{\mathrm{g}}$ is determined from the slope, the value of $\sigma_{\mathrm{e}}$ can be determined from $\sigma \sigma_{\mathrm{e}} / \sigma$, where $\sigma \sigma_{\mathrm{e}}$ can be calculated based on Eq. (2), and $\sigma$ is already estimated to be $11.3 \mathrm{erg} \mathrm{cm}^{-2}$ (depend markedly on the choice of $\Delta H_{\mathrm{f}}^{0}$ and the $\alpha$ parameter), which is a bit lower than the reported value of i-PP (ca. $11.5 \mathrm{erg} \mathrm{cm}^{-2}$ ). Finally, the $\bar{q}$ value can also be calculated from Eq. (5). Table 4 summarizes the values of $K_{\mathrm{g}}, \sigma \sigma_{\mathrm{e}}, \sigma_{\mathrm{e}}, \bar{q}$ and $G_{0}$, calculated based on the input parameters summarized in Table 3.

As shown in Fig. 3, the lines drawn through all sets of data within a given regime are roughly parallel. This is evidenced in the $K_{\mathrm{g}}$ values, taken directly from the slope of each line fit through each set of data. In the case of regime II, the $K_{\mathrm{g}}$ values lie in the range of $1.61 \times 10^{5}$ to $2.24 \times 10^{5} \mathrm{~K}^{2}$, whereas they are $3.57 \times 10^{5}$ to $3.70 \times 10^{5} \mathrm{~K}^{2}$ in regime III. The ratios of $K_{\mathrm{g}, \text {,II }} / K_{\mathrm{g}, \mathrm{II}}$ are in the range of $1.7-2.2$, which are close to the theoretical value of 2 . Table 4 also lists the $G_{0}$ values estimated for regimes II and III. The ratios of $G_{0, \text { III }} / G_{0, \mathrm{II}}$ 


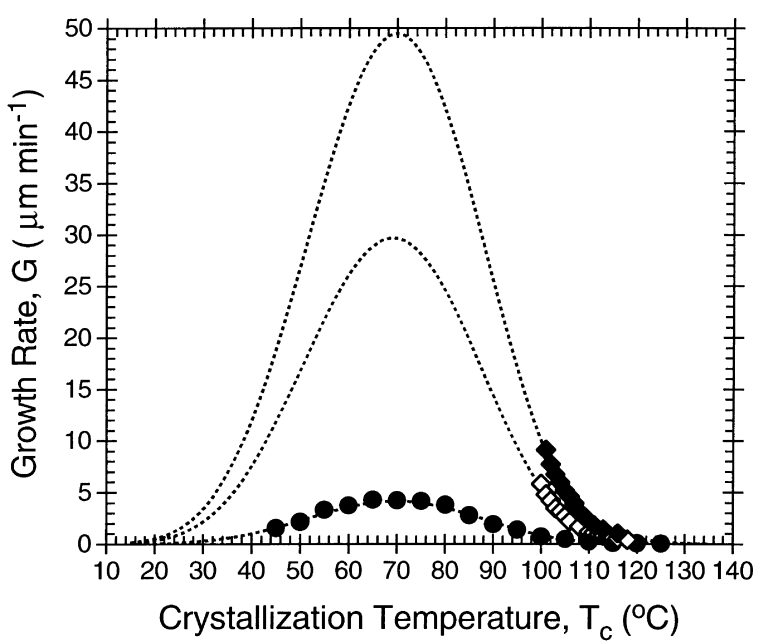

Fig. 4. Spherulitic growth rates of syndiotactic polypropylene as a function of crystallization temperatures: $(\bullet)$ data of Rodriguez-Arnold et al. (sample s-PP(8)) [19,21] (see footnote 1); $(\diamond)$ data of Rodriguez-Arnold et al. (sample s-PP(9)) [19,21] (see footnote 1); (৩) data of Supaphol et al. (sample s-PP\#1) [22]; (--) predicted values based on the growth rate expression (e.g. Eq. (1)) with appropriate $G_{0}$ and $K_{\mathrm{g}}$ values.

were also calculated and were found to be $1.05 \times 10^{3}$ to $1.21 \times 10^{4}$. In i-PP, Clark and Hoffman [7] found that $G_{0, \text { III }} / G_{0, \text { II }}$ values lie in the range of $3 \times 10^{3}$ to $3 \times 10^{4}$. Theoretically, the $G_{0, \text { III }} / G_{0, \text { II }}$ value can be calculated based on Eq. (27a) of Ref. [6]. Due to the lack of input information, we are unable to calculate the theoretical $G_{0, \text { III }} / G_{0, \text { II }}$ ratio at this point.

Assuming that the crystal growth is on the (010) plane for Cell II (or (020) plane for Cell III) (i.e. the $a c$ growth plane), the following values: $\sigma \sigma_{\mathrm{e}}=957.9 \pm 136.4 \mathrm{erg}^{2} \mathrm{~cm}^{-4}$, $\sigma_{\mathrm{e}}=84.9 \pm 12.1 \mathrm{erg} \mathrm{cm}^{-2}$, and $\bar{q}=9.9 \pm 1.4 \mathrm{kcal} \mathrm{mol}^{-1}$ are evaluated for regime II, and for regime III they are found to be $\sigma \sigma_{\mathrm{e}}=892.7 \pm 18.0 \mathrm{erg}^{2} \mathrm{~cm}^{-4}, \quad \sigma_{\mathrm{e}}=$ $79.1 \pm 1.6 \mathrm{erg} \mathrm{cm}^{-2}$, and $\bar{q}=9.2 \pm 0.2 \mathrm{kcal} \mathrm{mol}^{-1}$. In addition, when assuming that the crystal growth is on the (200) plane for either Cell II or III (i.e. the $b c$ growth plane), for regime II values of $\sigma \sigma_{\mathrm{e}}=739.9 \pm 105.3 \mathrm{erg}^{2} \mathrm{~cm}^{-4}$, $\sigma_{\mathrm{e}}=65.6 \pm 9.3 \mathrm{erg} \mathrm{cm}^{-2}$, and $\bar{q}=7.7 \pm 1.1 \mathrm{kcal} \mathrm{mol}^{-1}$ are evaluated, and they are $\sigma \sigma_{\mathrm{e}}=689.6 \pm 13.9 \mathrm{erg}^{2} \mathrm{~cm}^{-4}$, $\sigma_{\mathrm{e}}=61.1 \pm 1.2 \mathrm{erg} \mathrm{cm}^{-2}$, and $\bar{q}=7.1 \pm 0.1 \mathrm{kcal} \mathrm{mol}^{-1}$ for regime III. Obviously, the values calculated for the $b c$ growth plane are lower, and appear to be comparable to the values reported for i-PP (i.e. $\sigma \sigma_{\mathrm{e}}=740-790 \mathrm{erg}^{2} \mathrm{~cm}^{-4}$, $\sigma_{\mathrm{e}}=65-70 \mathrm{erg} \mathrm{cm}^{-2}$, and $\bar{q}=6.4-6.8 \mathrm{kcal} \mathrm{mol}^{-1}$ ) [7].

After the values of $K_{\mathrm{g}}$ and $G_{0}$ were identified, the function $G(T)$ can now be constructed using Eq. (1). This can be demonstrated by considering the case of s-PP\#1 as an example. According to the values of $K_{\mathrm{g}}$ and $G_{0}$ listed in Table 4, we find the following expressions:

$G_{\text {II }}\left(\mu \mathrm{m} \min ^{-1}\right)=7.52$

$$
\times 10^{4} \exp \left(-\frac{754.83}{\left(T_{\mathrm{c}}-T_{\infty}\right)}-\frac{1.61 \times 10^{5}}{T_{\mathrm{c}}(\Delta T) f}\right)
$$

which is valid at $T_{\mathrm{c}} \geq 110^{\circ} \mathrm{C}$, and

$$
\begin{aligned}
G_{\mathrm{III}}\left(\mu \mathrm{mmin}^{-1}\right)= & 9.07 \\
& \times 10^{8} \exp \left(-\frac{754.83}{\left(T_{\mathrm{c}}-T_{\infty}\right)}-\frac{3.58 \times 10^{5}}{T_{\mathrm{c}}(\Delta T) f}\right),
\end{aligned}
$$

which is valid at $T_{\mathrm{c}} \leq 110^{\circ} \mathrm{C}$. The growth rate expressions for s-PP(8) and s-PP(9) can also be obtained in a similar fashion as shown here. Fig. 4 shows the relationship between the linear growth rate of s-PP(8), s-PP(9) and s-PP\#1 samples and the crystallization temperature, with the calculated values (e.g. from Eqs. (6) and (7) for s-PP\#1) shown as the dotted curves. Interestingly, each calculated growth rate curve (with the exception of sample $6 \mathrm{H}$ ) exhibits a maximum at $T_{\mathrm{c}} \approx 70^{\circ} \mathrm{C}$, similar to that observed in the raw data of sample s-PP\#1. Consequently, this would make the maximum in $G(T)$ for s-PP occur at ca. $0.78\left(T_{\mathrm{m}}^{0}\right)_{100 \%}$.

\subsection{Effect of change in $T_{g}$}

A number of authors measured the glass transition temperature of s-PP samples to be around $0^{\circ} \mathrm{C}$ (i.e. $273.2 \mathrm{~K})[17,18,28]$, and it has also been used in the regime analysis by Miller and Seeley [17,18] and RodriguezArnold et al. [19,21]. Accordingly, we examine here the use of a $T_{\mathrm{g}}$ value of $273.2 \mathrm{~K}$ as input parameter, while all other parameters are kept unchanged. The input parameters thus are $T_{\infty}=T_{\mathrm{g}}-30=243.2 \mathrm{~K},\left(T_{\mathrm{m}}^{0}\right)_{100 \%}=441.8 \mathrm{~K}$, and $\Delta H_{\mathrm{f}}^{0}=8.0 \mathrm{~kJ} \mathrm{~mol}^{-1}$. Obviously, a slight increase in the $T_{\mathrm{g}}$ value (from 267.0 to $273.2 \mathrm{~K}$, equivalent to $2.3 \%$ increase in $T_{\mathrm{g}}$ value) causes a slight increase in the evaluated values of $K_{\mathrm{g}}$ and $G_{0}$, as shown in Table 5 . This change in $T_{\mathrm{g}}$ does not, however, have an effect on the position of the observed regime II $\rightarrow$ III transition. In addition, the ratio of $K_{\mathrm{g}, \text { III }} / K_{\mathrm{g}, \mathrm{II}}$ remains essentially unchanged.

According to Table 5, assuming that the crystal growth is on the (010) plane for Cell II (or (020) plane for Cell III) (i.e. the $a c$ growth plane), values of $\sigma \sigma_{\mathrm{e}}=975.3 \pm$ $138.9 \mathrm{erg}^{2} \mathrm{~cm}^{-4}, \quad \sigma_{\mathrm{e}}=86.4 \pm 12.3 \mathrm{erg} \mathrm{cm}^{-2}, \quad$ and $\bar{q}=$ $10.1 \pm 1.4 \mathrm{kcal} \mathrm{mol}^{-1}$ are evaluated for regime II, and are found to be $\sigma \sigma_{\mathrm{e}}=925.9 \pm 25.7 \mathrm{erg}^{2} \mathrm{~cm}^{-4}, \quad \sigma_{\mathrm{e}}=$ $82.0 \pm 2.3 \mathrm{erg} \mathrm{cm}^{-2}$, and $\bar{q}=9.6 \pm 0.3 \mathrm{kcal} \mathrm{mol}^{-1}$ for regime III. Further, when assuming that the crystal growth is on the (200) plane for either Cell II or Cell III (i.e. the $b c$ growth plane), for regime II values of $\sigma \sigma_{\mathrm{e}}=753.3 \pm 107.3$ $\mathrm{erg}^{2} \mathrm{~cm}^{-4}, \quad \sigma_{\mathrm{e}}=66.8 \pm 9.5 \mathrm{erg} \mathrm{cm}^{-2}, \quad$ and $\quad \bar{q}=7.8 \pm$ $1.1 \mathrm{kcal} \mathrm{mol}^{-1}$ are evaluated, and they are $\sigma \sigma_{\mathrm{e}}=$ $715.2 \pm 19.8 \mathrm{erg}^{2} \mathrm{~cm}^{-4}, \quad \sigma_{\mathrm{e}}=63.4 \pm 1.8 \mathrm{erg} \mathrm{cm}^{-2}$, and $\bar{q}=7.4 \pm 0.2 \mathrm{kcal} \mathrm{mol}^{-1}$ for regime III. By comparing the average values of corresponding parameters reported in Table 5 with those in Table 4 , we can conclude qualitatively that a $2.3 \%$ increase in the $T_{\mathrm{g}}$ results in approximately $2.9 \%$ increase in the $K_{\mathrm{g}}$ value, and about $2.6 \%$ increase in $\sigma \sigma_{\mathrm{e}}, \sigma_{\mathrm{e}}$ and $\bar{q}$ values. 
Table 5

Nucleation exponents crystal growth parameters based on the traditional regime analysis for the case: $T_{\mathrm{g}}=273.2 \mathrm{~K},\left(T_{\mathrm{m}}^{0}\right)_{100 \%}=441.8 \mathrm{~K}$, and $\Delta H_{\mathrm{f}}^{0}=8.0 \mathrm{~kJ}$ mol ${ }^{-1}$

\begin{tabular}{|c|c|c|c|c|c|c|c|c|c|c|}
\hline \multirow[t]{2}{*}{ Sample } & \multirow[b]{2}{*}{$K_{\mathrm{g}}\left(\mathrm{K}^{2}\right)$} & \multicolumn{3}{|l|}{$a c$ growth plane } & \multicolumn{3}{|l|}{$b c$ growth plane } & \multirow[b]{2}{*}{$G_{0}\left(\mu \mathrm{m} \min ^{-1}\right)$} & \multirow[b]{2}{*}{$G_{0, \mathrm{III}} / G_{0, \mathrm{II}}$} & \multirow[b]{2}{*}{$K_{\mathrm{g}, \mathrm{III}} / K_{\mathrm{g}, \mathrm{II}}$} \\
\hline & & $\sigma \sigma_{\mathrm{e}}\left(\mathrm{erg}^{2} \mathrm{~cm}^{-4}\right)$ & $\sigma_{\mathrm{e}}\left(\mathrm{erg} \mathrm{cm}^{-2}\right)$ & $\bar{q}\left(\mathrm{kcal} \mathrm{mol}^{-1}\right)$ & $\sigma \sigma_{\mathrm{e}}\left(\mathrm{erg}^{2} \mathrm{~cm}^{-4}\right)$ & $\sigma_{\mathrm{e}}\left(\mathrm{erg} \mathrm{cm}^{-2}\right)$ & $\bar{q}\left(\mathrm{kcal} \mathrm{mol}^{-1}\right)$ & & & \\
\hline \multicolumn{11}{|l|}{ Regime II } \\
\hline $6 \mathrm{H}$ & $1.85 \times 10^{5}$ & 915.3 & 81.1 & 9.5 & 707.0 & 62.7 & 7.3 & $5.51 \times 10^{6}$ & & \\
\hline s-PP(8) & $2.12 \times 10^{5}$ & 1045.8 & 92.7 & 10.8 & 807.8 & 71.6 & 8.4 & $1.11 \times 10^{7}$ & $1.64 \times 10^{3}$ & 1.7 \\
\hline s-PP(9) & $2.28 \times 10^{5}$ & 1127.0 & 99.9 & 11.7 & 870.5 & 77.1 & 9.0 & $1.42 \times 10^{7}$ & $1.19 \times 10^{3}$ & 1.7 \\
\hline s-PP\#1 & $1.65 \times 10^{5}$ & 813.0 & 72.0 & 8.4 & 628.0 & 55.7 & 6.5 & $1.10 \times 10^{5}$ & $3.38 \times 10^{4}$ & 2.3 \\
\hline \multicolumn{11}{|l|}{ Regime III } \\
\hline s-PP( $(8)$ & $3.64 \times 10^{5}$ & 898.3 & 79.6 & 9.3 & 693.9 & 61.5 & 7.2 & $1.81 \times 10^{10}$ & & \\
\hline s-PP(9) & $3.77 \times 10^{5}$ & 930.1 & 82.4 & 9.6 & 718.4 & 63.7 & 7.4 & $1.69 \times 10^{10}$ & & \\
\hline s-PP\#1 & $3.84 \times 10^{5}$ & 949.2 & 84.1 & 9.8 & 733.2 & 65.0 & 7.6 & $3.71 \times 10^{9}$ & & \\
\hline
\end{tabular}

Table 6

Nucleation exponents crystal growth parameters based on the traditional regime analysis for the case: $T_{\mathrm{g}}=273.2 \mathrm{~K},\left(T_{\mathrm{m}}^{0}\right)_{100 \%}=433.2 \mathrm{~K}$, and $\Delta H_{\mathrm{f}}^{0}=8.0 \mathrm{~kJ}$ mol ${ }^{-1}$

\begin{tabular}{|c|c|c|c|c|c|c|c|c|c|c|}
\hline \multirow[t]{2}{*}{ Sample } & \multirow[b]{2}{*}{$K_{\mathrm{g}}\left(\mathrm{K}^{2}\right)$} & \multicolumn{3}{|l|}{$a c$ growth plane } & \multicolumn{3}{|l|}{$b c$ growth plane } & \multirow[b]{2}{*}{$G_{0}\left(\mu \mathrm{m} \min ^{-1}\right)$} & \multirow[b]{2}{*}{$G_{0, \mathrm{III}} / G_{0, \mathrm{II}}$} & \multirow[b]{2}{*}{$K_{\mathrm{g}, \mathrm{III}} / K_{\mathrm{g}, \mathrm{II}}$} \\
\hline & & $\sigma \sigma_{\mathrm{e}}\left(\mathrm{erg}^{2} \mathrm{~cm}^{-4}\right)$ & $\sigma_{\mathrm{e}}\left(\mathrm{erg} \mathrm{cm}^{-2}\right)$ & $\bar{q}\left(\mathrm{kcal} \mathrm{mol}^{-1}\right)$ & $\sigma \sigma_{\mathrm{e}}\left(\mathrm{erg}^{2} \mathrm{~cm}^{-4}\right)$ & $\sigma_{\mathrm{e}}\left(\mathrm{erg} \mathrm{cm}^{-2}\right)$ & $\bar{q}\left(\mathrm{kcal} \mathrm{mol}^{-1}\right)$ & & & \\
\hline \multicolumn{11}{|l|}{ Regime II } \\
\hline $6 \mathrm{H}$ & $1.15 \times 10^{5}$ & 581.6 & 51.5 & 6.0 & 449.2 & 39.8 & 4.7 & $4.77 \times 10^{5}$ & & \\
\hline s-PP(8) & $1.45 \times 10^{5}$ & 732.3 & 64.9 & 7.6 & 565.6 & 50.1 & 5.9 & $1.40 \times 10^{6}$ & $7.16 \times 10^{2}$ & 1.8 \\
\hline s-PP(9) & $1.56 \times 10^{5}$ & 786.5 & 69.7 & 8.1 & 607.5 & 53.8 & 6.3 & $1.49 \times 10^{6}$ & $5.61 \times 10^{2}$ & 1.7 \\
\hline s-PP\#1 & $1.09 \times 10^{5}$ & 547.9 & 48.5 & 5.7 & 423.2 & 37.5 & 4.4 & $1.72 \times 10^{4}$ & $2.08 \times 10^{4}$ & 2.7 \\
\hline \multicolumn{11}{|l|}{ Regime III } \\
\hline s-PP(8) & $2.62 \times 10^{5}$ & 658.7 & 58.4 & 6.8 & 508.8 & 45.1 & 5.3 & $1.00 \times 10^{9}$ & & \\
\hline s-PP(9) & $2.71 \times 10^{5}$ & 681.4 & 60.4 & 7.1 & 526.3 & 46.6 & 5.5 & $8.34 \times 10^{8}$ & & \\
\hline s-PP\#1 & $2.90 \times 10^{5}$ & 731.6 & 64.8 & 7.6 & 565.1 & 50.1 & 5.9 & $3.57 \times 10^{8}$ & & \\
\hline
\end{tabular}




\subsection{Effect of change in $\left(T_{\mathrm{m}}^{0}\right)_{100 \%}$}

A number of authors [17,18,20,21,28,29] have reported the $T_{\mathrm{m}}^{0}$ values of s-PP samples with different syndiotacticity levels. Only reported values with known concentration of racemic pentads [\% rrrr] will be discussed here. These values of $T_{\mathrm{m}}^{0}$, with the syndiotacticity level in parentheses, are $160^{\circ} \mathrm{C}(86 \%)$ [20,21] and $150-186^{\circ} \mathrm{C}(89-95 \%)$ [29]. Obviously, the $T_{\mathrm{m}}^{0}$ values are strongly dependent on the syndiotacticity levels. Theoretically, the $T_{\mathrm{m}}^{0}$ values measured for a s-PP sample with a particular syndiotacticity level is presumably the melting point of $100 \%$ crystallinity crystals. In terms of regime analysis, using different $T_{\mathrm{m}}^{0}$ values in the analysis may lead to anomalous results, as the crystal growth parameters are very sensitive to the $T_{\mathrm{m}}^{0}$ values (as will be shown subsequently). With this in mind, use of $\left(T_{\mathrm{m}}^{0}\right)_{100 \%}$ in the analysis is thus preferable, and this is the reason why the $\left(T_{\mathrm{m}}^{0}\right)_{100 \%}$ value of $168.7^{\circ} \mathrm{C}(441.8 \mathrm{~K})$ [27] has been used in this paper.

To illustrate the effect of change in $\left(T_{\mathrm{m}}^{0}\right)_{100 \%}$, a value of $160^{\circ} \mathrm{C}(433.2 \mathrm{~K})$ was used in the analysis. It is worth noting that this value was used in the analysis by Rodriguez-Arnold et al. [19,21], and is very close to the value of $161^{\circ} \mathrm{C}(434.2 \mathrm{~K})$ used by Miller and Seeley $[17,18]$. Thus, the input parameters used in this case are $T_{\infty}=T_{\mathrm{g}}-30=243.2 \mathrm{~K}, \quad\left(T_{\mathrm{m}}^{0}\right)_{100 \%}=433.2 \mathrm{~K}$, and $\Delta H_{\mathrm{f}}^{0}=8.0 \mathrm{~kJ} \mathrm{~mol}^{-1}$. Obviously, the decrease in the $\left(T_{\mathrm{m}}^{0}\right)_{100 \%}$ value (from 441.8 to $433.2 \mathrm{~K}$, equivalent to roughly $2.0 \%$ decrease in $\left(T_{\mathrm{m}}^{0}\right)_{100 \%}$ value) causes a marked decrease in the values of $K_{\mathrm{g}}$ and $G_{0}$, as shown in Table 6. This change in $\left(T_{\mathrm{m}}^{0}\right)_{100 \%}$ does not, however, have any effect on the position of the observed regime $\mathrm{II} \rightarrow$ III transition. The ratios of $K_{\mathrm{g}, \mathrm{III}} / K_{\mathrm{g}, \mathrm{II}}$ are found to lie between 1.7 and 2.7 .

According to Table 6, assuming that the crystal growth is on the (010) plane for Cell II (or (020) plane for Cell III), i.e. the $a c$ growth plane, for regime II values of $\sigma \sigma_{\mathrm{e}}=$ $662.1 \pm 115.4 \mathrm{erg}^{2} \mathrm{~cm}^{-4}, \sigma_{\mathrm{e}}=58.7 \pm 10.2 \mathrm{erg} \mathrm{cm}^{-2}$, and $\bar{q}=6.9 \pm 1.2 \mathrm{kcal} \mathrm{mol}^{-1}$ are evaluated, and they are $\sigma \sigma_{\mathrm{e}}=690.6 \pm 37.3 \mathrm{erg}^{2} \mathrm{~cm}^{-4}, \sigma_{\mathrm{e}}=61.2 \pm 3.3 \mathrm{erg} \mathrm{cm}^{-2}$, and $\bar{q}=7.2 \pm 0.4 \mathrm{kcal} \mathrm{mol}^{-1}$ for regime III. Additionally, when assuming the crystal growth to be on the (200) plane for either Cell II or Cell III, i.e. the $b c$ growth plane, for regime II values of $\sigma \sigma_{\mathrm{e}}=511.4 \pm 89.1 \mathrm{erg}^{2} \mathrm{~cm}^{-4}$, $\sigma_{\mathrm{e}}=45.3 \pm 7.9 \mathrm{erg} \mathrm{cm}^{-2}$, and $\bar{q}=5.3 \pm 0.9 \mathrm{kcal} \mathrm{mol}^{-1}$ are evaluated, and they are $\sigma \sigma_{\mathrm{e}}=533.4 \pm 28.8 \mathrm{erg}^{2} \mathrm{~cm}^{-4}$ $\sigma_{\mathrm{e}}=47.3 \pm 2.6 \mathrm{erg} \mathrm{cm}^{-2}$, and $\bar{q}=5.5 \pm 0.3 \mathrm{kcal} \mathrm{mol}^{-1}$ for regime III. By comparing the average values of the corresponding parameters reported in Table 6 with those in Table 5, we can conclude qualitatively that a $2.0 \%$ decrease in $\left(T_{\mathrm{m}}^{0}\right)_{100 \%}$ value results in approximately $29.6 \%$ decrease in the $K_{\mathrm{g}}$ value, and about $29.3 \%$ decrease in $\sigma \sigma_{\mathrm{e}}$, $\sigma_{\mathrm{e}}$, and $\bar{q}$ values. We have also estimated that a $1{ }^{\circ} \mathrm{C}$ change in $\left(T_{\mathrm{m}}^{0}\right)_{100 \%}$ value leads to approximately $4.4 \%$ change in $K_{\mathrm{g}}$, $\sigma \sigma_{\mathrm{e}}, \sigma_{\mathrm{e}}$, and $\bar{q}$ values.

\subsection{Effect of change in $\Delta H_{\mathrm{f}}^{0}$}

Intuitively, one can predict based on Eqs. (1), (2), (4) and (5) that the change in $\Delta H_{\mathrm{f}}^{0}$ value does not affect the $K_{\mathrm{g}}, \sigma_{\mathrm{e}}$ and $\bar{q}$ values. Only the $\sigma$ parameter is found to be sensitive to the change in $\Delta H_{\mathrm{f}}^{0}$ value. If other input parameters are kept unchanged $\left(T_{\infty}=T_{\mathrm{g}}-30=243.2 \mathrm{~K} \quad\right.$ and $\left.\left(T_{\mathrm{m}}^{0}\right)_{100 \%}=433.2 \mathrm{~K}\right)$, the change of $\Delta H_{\mathrm{f}}^{0}$ from 8.0 [19-21] to $8.3 \mathrm{~kJ} \mathrm{~mol}^{-1}$ [28] leads to a change of lateral surface free energy from 11.3 to $11.7 \mathrm{erg} \mathrm{cm}^{-2}$. This corresponds to a $3.5 \%$ increase in the $\sigma$ value, as a result of $3.3 \%$ increase in the $\Delta H_{\mathrm{f}}^{0}$ value. In addition, if the $\Delta H_{\mathrm{f}}^{0}$ value of $3.1 \mathrm{~kJ} \mathrm{~mol}^{-1}$ $[17,18]$ is used instead, the $\sigma$ value decreases from 11.3 to $4.4 \mathrm{erg} \mathrm{cm}^{-2}$, which equals the reported value by Miller and Seeley $[17,18]$. This corresponds to a $61.1 \%$ decrease in the $\sigma$ value, as a result of $60.8 \%$ decrease in the $\Delta H_{\mathrm{f}}^{0}$ value. Based on these results, it can be construed that a $1 \%$ change in the $\Delta H_{\mathrm{f}}^{0}$ value causes a $1 \%$ change in the resulting $\sigma$ value. It is worth noting that the $K_{\mathrm{g}}, \sigma_{\mathrm{e}}$ and $\bar{q}$ values are the same set as those reported in Table 6.

\section{Further discussion of the literature}

Miller and Seeley [17,18] analyzed their data based on regime II crystallization using the following input parameters: $\quad T_{\mathrm{g}}=273.2 \mathrm{~K}, \quad\left(T_{\mathrm{m}}^{0}\right)_{100 \%}=434.2 \mathrm{~K}, \quad$ and $\Delta H_{\mathrm{f}}^{0}=3.1 \mathrm{~kJ} \mathrm{~mol}^{-1}$. They found the crystal growth parameters to be: $\sigma=4.4 \mathrm{erg} \mathrm{cm}^{-2}, \quad \sigma \sigma_{\mathrm{e}}=256$ $\mathrm{erg}^{2} \mathrm{~cm}^{-4}, \quad \sigma_{\mathrm{e}}=58 \mathrm{erg} \mathrm{cm}^{-2}, \quad$ and $\bar{q}=6.8 \mathrm{kcal} \mathrm{mol}^{-1}$. We also calculated the crystal growth parameters based on their use of input parameters and found that they are $\sigma=4.4 \mathrm{erg} \mathrm{cm}^{-2}, \quad \sigma \sigma_{\mathrm{e}}=241.9 \mathrm{erg}^{2} \mathrm{~cm}^{-4}$, $\sigma_{\mathrm{e}}=54.7 \mathrm{erg} \mathrm{cm}^{-2}, \quad$ and $\bar{q}=6.4 \mathrm{kcal} \mathrm{mol}^{-1}$, when considering that (010) or (020) is the growth plane based on either Cell II or Cell III (i.e. the $a c$ growth plane), respectively; and they are $\sigma=4.4 \mathrm{erg} \mathrm{cm}^{-2}$, $\sigma \sigma_{\mathrm{e}}=186.9 \mathrm{erg}^{2} \mathrm{~cm}^{-4}, \quad \sigma_{\mathrm{e}}=42.2 \mathrm{erg} \mathrm{cm}^{-2}, \quad$ and $\bar{q}=4.9 \mathrm{kcal} \mathrm{mol}^{-1}$, when considering (200) to be the growth plane based on either Cell II or Cell III (i.e. the $b c$ growth plane). At the time of publication though, only the high temperature orthorhombic form I (Cell I) [30] was available, and they accordingly assumed that the growth plane occurred on the (110) plane. With this in mind, we re-evaluated the crystal growth parameters, based on $a_{0}=7.77 \times 10^{-8} \mathrm{~cm}$ and $b_{0}=5.22 \times 10^{-8} \mathrm{~cm}$, and found that they are $\sigma=4.4 \mathrm{erg} \mathrm{cm}^{-2}, \sigma \sigma_{\mathrm{e}}=259.5$ $\operatorname{erg}^{2} \mathrm{~cm}^{-4}, \sigma_{\mathrm{e}}=58.7 \mathrm{erg} \mathrm{cm}^{-2}$, and $\bar{q}=6.9 \mathrm{kcal} \mathrm{mol}^{-1}$, which is extremely close to their published values.

In the case of Rodriguez-Arnold et al. [19,21], instead of performing a typical LH regime plot, they analyzed their data by a construction of the modified regime plot $\log G-$ $\log \Delta T+U^{*} / 2.303 R\left(T_{\mathrm{c}}-T_{\infty}\right)$ versus $1 / 2.303 T_{\mathrm{c}}(\Delta T) f$. In this case, $K_{\mathrm{g}}$ and $G_{0}$ can still be obtained as they normally would with the traditional plot. In their analysis, the input parameters are: $T_{\mathrm{g}}=273.2 \mathrm{~K},\left(T_{\mathrm{m}}^{0}\right)_{100 \%}=433.2 \mathrm{~K}$, and 


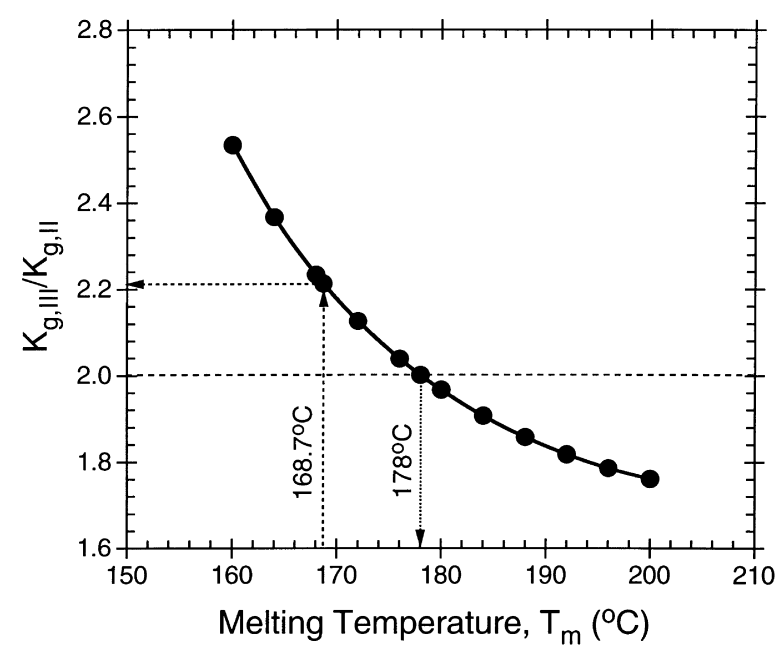

Fig. 5. Variation of the $K_{\mathrm{g}, \mathrm{III}} / K_{\mathrm{g}, \mathrm{II}}$ value as a result of changes in the seed equilibrium melting temperature $T_{\mathrm{m}}^{0}$ of sample s-PP\#1. The seed $T_{\mathrm{m}}^{0}$ value which results in the $K_{\mathrm{g}, \mathrm{III}} / K_{\mathrm{g}, \mathrm{II}}$ value of 2.0 (ca. $178^{\circ} \mathrm{C}$ ) is supposed to be the true equilibrium melting temperature of sample s-PP\#1.

$\Delta H_{\mathrm{f}}^{0}=8.0 \mathrm{~kJ} \mathrm{~mol}^{-1}$. As they proposed that the growth occurs on the (200) plane (i.e. the $b c$ growth plane), we have also re-analyzed their data accordingly, and have found that the crystal growth parameters for s-PP(8) and s-PP(9) samples, based on $K_{\mathrm{g}}$ values taken from the modified regime plots, are $\sigma=11.3 \mathrm{erg} \mathrm{cm}^{-2}, \sigma \sigma_{\mathrm{e}}=460.4-$ $527.9 \mathrm{erg}^{2} \mathrm{~cm}^{-4}, \quad \sigma_{\mathrm{e}}=42.4-46.8 \mathrm{erg} \mathrm{cm}^{-2}, \quad$ and $\bar{q}=$ $4.8-5.5 \mathrm{kcal} \mathrm{mol}^{-1}$. These values are found to be in good agreement with their original results (i.e. $\sigma=11.2 \mathrm{erg} \mathrm{cm}^{-2}, \sigma \sigma_{\mathrm{e}}=465.9-537.6 \mathrm{erg}^{2} \mathrm{~cm}^{-4}, \sigma_{\mathrm{e}}=$ 41.8-47.7 $\mathrm{erg} \mathrm{cm}^{-2}, \quad$ and $\quad \bar{q}=4.9-5.6 \mathrm{kcal} \mathrm{mol}^{-1}$ ) [19,21]. Apparently, the values obtained for s-PP(8) and $\mathrm{s}-\mathrm{PP}(9)$ using the modified regime analysis are much lower than those obtained using the traditional approach (cf. Table 6). Qualitatively, the difference in the obtained values accounts for a $12.0 \%$ decrease in the $K_{\mathrm{g}}$ value, and about $12.6 \%$ decrease in the $\sigma \sigma_{\mathrm{e}}, \sigma_{\mathrm{e}}$ and $\bar{q}$ values.

Even though the theoretical background of the modified regime analysis applied by Rodriguez-Arnold et al. [19,21] is not entirely clear, we find it very interesting to analyze the linear growth rate data based on our reference input parameters (i.e. $T_{\mathrm{g}}=267.0 \mathrm{~K},\left(\left(T_{\mathrm{m}}^{0}\right)_{100 \%}-441.8 \mathrm{~K}\right.$, and $\left.\Delta H_{\mathrm{f}}^{0}=8.0 \mathrm{~kJ} \mathrm{~mol}^{-1}\right)$ using the modified regime analysis and compare the results with those analyzed using the traditional approach which are listed in Table 4. Assuming that the crystal growth is on the (010) plane for Cell II (or (020) plane for Cell III), i.e. the $a c$ growth plane, the values of $\quad \sigma \sigma_{\mathrm{e}}=839.4 \pm 129.5 \mathrm{erg}^{2} \mathrm{~cm}^{-4}, \quad \sigma_{\mathrm{e}}=74.4 \pm 11.5$ erg cm${ }^{-2}$, and $\bar{q}=8.7 \pm 1.3 \mathrm{kcal} \mathrm{mol}^{-1}$ are found for regime II, and they are $\sigma \sigma_{\mathrm{e}}=807.8 \pm 30.8 \mathrm{erg}^{2} \mathrm{~cm}^{-4}$, $\sigma_{\mathrm{e}}=71.6 \pm 2.7 \mathrm{erg} \mathrm{cm}^{-2}$, and $\bar{q}=8.4 \pm 0.3 \mathrm{kcal} \mathrm{mol}^{-1}$ for regime III. In addition, when assuming that the crystal growth is on the (200) plane for either Cell II or Cell III, i.e. the $b c$ growth plane, the values of $\sigma \sigma_{\mathrm{e}}=648.3 \pm$ $100.0 \mathrm{erg}^{2} \mathrm{~cm}^{-4}, \quad \sigma_{\mathrm{e}}=57.5 \pm 8.9 \mathrm{erg} \mathrm{cm}^{-2}, \quad$ and $\bar{q}=$
$6.7 \pm 1.0 \mathrm{kcal} \mathrm{mol}^{-1}$ are determined for regime II, and they are $\sigma \sigma_{\mathrm{e}}=623.9 \pm 23.8 \mathrm{erg}^{2} \mathrm{~cm}^{-4}, \sigma_{\mathrm{e}}=55.3 \pm 2.1$ erg cm${ }^{-2}$, and $\bar{q}=6.5 \pm 0.2 \mathrm{kcal} \mathrm{mol}^{-1}$ for regime III. It is obvious that the crystal growth parameters obtained using the modified regime analysis are much lower than those obtained using the traditional approach (cf. Table 4). Qualitatively, the difference in the obtained values accounts for a $10.7 \%$ decrease in the $K_{\mathrm{g}}$ value, and about $11.2 \%$ decrease in the $\sigma \sigma_{\mathrm{e}}, \sigma_{\mathrm{e}}$, and $\bar{q}$ values.

\section{Further discussion on the $T_{\mathrm{m}}^{0}$ value used in the analysis}

Recently, Huang et al. [31] suggested that analysis of the linear growth rate data of polymers in the context of the $\mathrm{LH}$ secondary nucleation theory can only be carried out successfully when the equilibrium melting temperature $T_{\mathrm{m}}^{0}$ for the polymer of interest can be determined accurately. They also suggested that the $T_{\mathrm{m}}^{0}$ value for the polymer of interest can be evaluated directly from the growth rate data, using the LH secondary nucleation theory as basis. By considering $T_{\mathrm{m}}^{0}$ as a variable, they assumed that the true $T_{\mathrm{m}}^{0}$ value for the polymer of interest is taken as the value that gives the lowest variance between the experimental values (i.e. the LHS values of Eq. (3)) and the linear regression values (i.e. the RHS values of Eq. (3)). Their proposed method is hereafter called the "data-fitting" procedure. So far, this method has been successfully applied to the cases of poly(pivalolactone) [31] and its blends [31,32], isotactic polystyrene [33], poly(L-lactide-co-meso-lactide) copolymers [34], and isotactic polypropylene [35].

An alternative method in determining the true $T_{\mathrm{m}}^{0}$ value for the polymer of interest can be found based on the theoretical requirement of the ratios $K_{\mathrm{g}, \mathrm{I}} / K_{\mathrm{g}, \mathrm{II}}=K_{\mathrm{g}, \mathrm{III}} / K_{\mathrm{g}, \mathrm{II}}=2.0$, provided that either regime I $\rightarrow$ II or regime II $\rightarrow$ III transition exists within the temperature range of interest. By assuming that the LH secondary nucleation theory can be applied to describe the temperature dependence of the growth rate data of polymers, other than that of polyethylene which is the basis for the development of theory, and that the measured growth rate data is of high quality, the true $T_{\mathrm{m}}^{0}$ value for the polymer of interest is taken as the value which results in the ratio of the corresponding nucleation exponents of 2.0. Xu et al. [35] applied both the alternative approaches of the data-fitting procedure on the growth rate data of isotactic polypropylene, and found that the resulting $T_{\mathrm{m}}^{0}$ values from both approaches are comparable (ca. $\left.215^{\circ} \mathrm{C}\right)$.

In this paper, we apply the second alternative approach of the data-fitting procedure to the growth rate data of s-PP\#1 to determine the true $T_{\mathrm{m}}^{0}$ value which results in the $K_{\mathrm{g}, \text { III }} / K_{\mathrm{g}, \text { II }}$ value of 2.0. By varying the seed $T_{\mathrm{m}}^{0}$ value $\left(U^{*}=1500\right.$ cal mol ${ }^{-1}$ and $T_{\infty}=267.30 \mathrm{~K}$ ), the corresponding value of $K_{\mathrm{g}, \mathrm{III}} / K_{\mathrm{g}, \mathrm{II}}$ also varies, and is found to decrease with increasing seed $T_{\mathrm{m}}^{0}$ value (cf. Fig. 5). According to Fig. 5, the true $T_{\mathrm{m}}^{0}$ value which results in the value of $K_{\mathrm{g}, \mathrm{III}} / K_{\mathrm{g}, \mathrm{II}}$ of 2.0 is 
approximately $178^{\circ} \mathrm{C}$. Based on this new $T_{\mathrm{m}}^{0}$ value, the resulting nucleation parameters, $K_{\mathrm{g}, \text { II }}$ or $0.5 K_{\mathrm{g}, \mathrm{III}}$, were found to be $2.36 \times 10^{5} \mathrm{~K}^{2}$. Using the same input parameters summarized in Table 3, the crystal growth parameters characteristic of the LH growth theory can be calculated accordingly. Assuming that growth occurs on the $a c$ plane, values of $\sigma \sigma_{\mathrm{e}}=1109.0 \mathrm{erg}^{2} \mathrm{~cm}^{-4}, \quad \sigma_{\mathrm{e}}=101.2$ erg cm${ }^{-2}$, and $\bar{q}=11.8 \mathrm{kcal} \mathrm{mol}^{-1}$ are found, whereas they are $\sigma \sigma_{\mathrm{e}}=856.6 \mathrm{erg}^{2} \mathrm{~cm}^{-4}, \sigma_{\mathrm{e}}=78.2 \mathrm{erg} \mathrm{cm}^{-2}$, and $\bar{q}=9.1 \mathrm{kcal} \mathrm{mol}^{-1}$ when assuming that growth occurs on the $b c$ plane. Clearly, these values are much greater than those listed in Table 4, due to the effect of the much higher $T_{\mathrm{m}}^{0}$ value used (i.e. $178^{\circ} \mathrm{C}$ versus $168.7^{\circ} \mathrm{C}$ ).

One of the precautionary notes given by Huang et al. [31] is that the data-fitting procedure may be only applicable for growth rate data measured in a temperature range far from the glass transition temperature (i.e. in the nucleation control region) in order to minimize the influence from the transport term. As our raw data cover both the regions, the effect of changes in parameters governing the transport term (i.e. $U^{*}$ and $T_{\infty}$ ) should also be considered. Qualitatively, an increase of $2.3 \%$ in the $T_{\mathrm{g}}$ value resulted in an increase of $3.9 \%$ in the resulting $T_{\mathrm{m}}^{0}$ value and of approximately $30 \%$ in all the corresponding crystal growth parameters, whereas an increase of $8.3 \%$ in $U^{*}$ value resulted in an increase of $2.3 \%$ in the resulting $T_{\mathrm{m}}^{0}$ value and of approximately $17 \%$ in all the corresponding crystal growth parameters [36]. Due to the fact that the $T_{\mathrm{m}}^{0}$ value estimated from the data-fitting method is much greater than the one we estimated in an earlier work [27], more careful investigation into this matter is currently underway.

\section{Summary and conclusions}

Spherulitic growth rate data of syndiotactic polypropylenes were taken from the literature and analyzed based on the traditional LH regime plot of $\log G+U^{*}$ / $2.303 R\left(T_{\mathrm{c}}-T_{\infty}\right)$ versus $1 / 2.303 T_{\mathrm{c}}(\Delta T) f$. The input parameters used in the analysis were $T_{\mathrm{g}}=267.0 \mathrm{~K}$, $\left(T_{\mathrm{m}}^{0}\right)_{100 \%}=441.8 \mathrm{~K}$, and $\Delta H 0=8.0 \mathrm{~kJ} \mathrm{~mol}^{-1}$. Except for the data of $6 \mathrm{H}$ sample, all of the straight lines drawn through the bulk of data of s-PP(8), s-PP(9), and s-PP\#1 samples exhibited an unmistakable upward change in slopes, corresponding to the regime II $\rightarrow$ III transition, at the crystallization temperature of $110^{\circ} \mathrm{C}$. The ratios of the $K_{\mathrm{g}, \text { III }} / K_{\mathrm{g}, \text { II }}$ were found to be in the range of 1.7-2.2. Based on these input parameters, the average values of the crystal growth parameters, regardless of the regime considered, were found to be $\sigma=11.3 \mathrm{erg} \mathrm{cm}^{-2}, \quad \sigma \sigma_{\mathrm{e}}=930.0 \pm 103.1 \mathrm{erg}^{2} \mathrm{~cm}^{-4}$, $\sigma_{\mathrm{e}}=82.4 \pm 9.1 \mathrm{erg} \mathrm{cm}^{-2}$, and $\bar{q}=9.6 \pm 1.1 \mathrm{kcal} \mathrm{mol}^{-1}$, when assuming that growth occurs on the $a c$ plane. However, when we assume that growth occurs on the $b c$ plane, they were $\sigma \sigma_{\mathrm{e}}=718.3 \pm 79.6 \mathrm{erg}^{2} \mathrm{~cm}^{-4}, \sigma_{\mathrm{e}}=$ $63.7 \pm 7.1 \mathrm{erg} \mathrm{cm}^{-2}$, and $\bar{q}=7.4 \pm 0.8 \mathrm{kcal} \mathrm{mol}^{-1}$.

The growth rate data were also analyzed based on the modified regime plot of $\log G-\log \Delta T+U^{*} /$ $2.303 R\left(T_{\mathrm{c}}-T_{\infty}\right)$ versus $1 / 2.303 T_{\mathrm{c}}(\Delta T) f$, as suggested by Rodriguez-Arnold and her coworkers $[19,21]$ using the same set of input parameters. Based on this analysis, the position of the regime II $\rightarrow$ III transition and the ratios of the $K_{\mathrm{g}, \mathrm{III}} / K_{\mathrm{g}, \mathrm{II}}$ were essentially unaffected. Only the parameters characteristic of the crystal growth were found to be lower in their values; these exhibited as much as $10.7 \%$ decrease in the $K_{\mathrm{g}}$ value and about $11.2 \%$ decrease in the $\sigma \sigma_{\mathrm{e}}, \sigma_{\mathrm{e}}$ and $\bar{q}$ values. Specifically, the average values of the crystal growth parameters regardless of the regime considered were found to be $\sigma=11.3 \mathrm{erg} \mathrm{cm}^{-2}, \quad \sigma \sigma_{\mathrm{e}}=825.8 \pm 94.8 \mathrm{erg}^{2} \mathrm{~cm}^{-4}, \sigma_{\mathrm{e}}=$ $73.2 \pm 8.4 \mathrm{erg} \mathrm{cm}^{-2}$, and $\bar{q}=8.6 \pm 1.0 \mathrm{kcal} \mathrm{mol}^{-1}$, when assuming that the $a c$ plane is the growth plane. However, when assuming that the $b c$ plane is the growth plane, they were $\sigma \sigma_{\mathrm{e}}=637.9 \pm 73.2 \mathrm{erg}^{2} \mathrm{~cm}^{-4}, \sigma_{\mathrm{e}}=56.5 \pm 6.5$ erg cm${ }^{-2}$, and $\bar{q}=6.6 \pm 0.8 \mathrm{kcal} \mathrm{mol}^{-1}$.

The measured crystal growth parameters were found to be sensitive to the values of the input parameters used, especially the equilibrium melting temperature. Qualitatively, we found that a $2.3 \%$ change in the $T_{\mathrm{g}}$ value leads to an approximately $2.9 \%$ change in the $K_{\mathrm{g}}$ value, and around $2.6 \%$ change in $\sigma \sigma_{\mathrm{e}}, \sigma_{\mathrm{e}}$ and $\bar{q}$ values. In the case of $\left(T_{\mathrm{m}}^{0}\right)_{100 \%}$, we found that a $2.0 \%$ change in its value causes a $29.6 \%$ change in the $K_{\mathrm{g}}$ value, and around $29.3 \%$ change in $\sigma \sigma_{\mathrm{e}}, \sigma_{\mathrm{e}}$ and $\bar{q}$ values. Alternatively, a $1^{\circ} \mathrm{C}$ change in the $\left(T_{\mathrm{m}}^{0}\right)_{100 \%}$ value causes an approximately $4.4 \%$ change in the $K_{\mathrm{g}}, \sigma \sigma_{\mathrm{e}}, \sigma_{\mathrm{e}}$, and $\bar{q}$ values. Lastly, a $1 \%$ change in the $\Delta H_{\mathrm{f}}^{0}$ value results in a roughly $1 \%$ change in the $\sigma$ value, while other parameters are unaffected.

\section{References}

[1] Lauritzen Jr. JI, Hoffman JD. J Res Natl Bur Stand 1960;A64:73.

[2] Hoffman JD, Lauritzen Jr. JI. J Res Natl Bur Stand 1961;A65:297.

[3] Lauritzen Jr. JI, Hoffman JD. J Appl Phys 1973;44:4340.

[4] Hoffman JD, Davis GT, Lauritzen Jr. JI. Chapter 7. In: Hannay NB, editor. Treatise on solid state chemistry, vol. 3. New York: Plenum, 1976.

[5] Hoffman JD. Polymer 1982;23:656.

[6] Hoffman JD. Polymer 1983;24:3.

[7] Clark EJ, Hoffman JD. Macromolecules 1984;17:878.

[8] Hoffman JD, Miller RL. Macromolecules 1988;21:3038.

[9] Hoffman JD. Polymer 1992;33:2643.

[10] Hoffman JD, Miller RL. Polymer 1997;38:3151.

[11] Vasanthakumari R, Pennings AJ. Polymer 1983;24:175.

[12] Pelzbauer Z, Galeski A. J Polym Sci 1972;C38:23.

[13] Phillips PJ, Vatansever N. Macromolecules 1987;20:2138.

[14] Fatou JG, Marco C, Mandelkern L. Polymer 1990;31:1685.

[15] Supaphol P, Spruiell JE. J Polym Sci, Polym Phys 1998;36:681.

[16] Phillips PJ, Lambert WS. Macromolecules 1990;23:2075.

[17] Miller RL, Seeley EG. J Polym Sci, Polym Phys 1982;20:2297.

[18] Seeley EG. MS thesis, Central Michigan University, 1982.

[19] Rodriguez-Arnold J, Bu Z, Cheng SZD, Hsieh ET, Johnson TW, Geerts RG, Palackal SJ, Hawley GR, Welch MB. Polymer 1994;35(24):5194.

[20] Rodriguez-Arnold J, Zhang A, Cheng SZD, Lovinger AJ, Hsieh ET, Chu P, Johnson TW, Honnell KG, Geerts RG, Palackal SJ, Hawley GR, Welch MB. Polymer 1994;35(9):1884.

[21] Rodriguez-Arnold J. PhD dissertation, University of Akron, 1994. 
[22] Supaphol P, Hwu JJ, Phillips PJ, Spruiell JE. In: Proceedings of the 55th Annual Technical Conference (ANTEC), Society of Plastics Engineers, 1997. p. 1759.

[23] Supaphol P, Spruiell JE. In preparation.

[24] Lotz B, Lovinger AJ, Cais RE. Macromolecules 1988;21:2375.

[25] Lovinger AJ, Lotz B, Davis DD. Polym Prepr 1992;33:270.

[26] Thomas DG, Staveley LAK. J Chem Soc 1952;4569.

[27] Supaphol P, Spruiell JE. J Appl Polym Sci, accepted.

[28] Haftka S, Könnecke K. J Macromol Sci Phys 1991;B30(4):319.

[29] Balbontin G, Dainelli D, Galimberti M, Paganetto G. Makromol Chem 1992;193:693.

[30] Corradini P, Natta G, Ganis P, Temussi PA. J Polym Sci 1967;C16:2477.
[31] Huang J, Prasad A, Marand H. Polymer 1994;35(9):1896.

[32] Huang J, Marand H. Macromolecules 1997;30:1069.

[33] Iler HD. PhD dissertation, Virginia Institute of Technology and State University, 1995.

[34] Huang J, Lisowski MS, Runt J, Hall ES, Kean RT, Buehler N, Lin JS. Macromolecules 1998;31:2593.

[35] Xu J, Srinivas S, Marand H, Agarwal P. Macromolecules 1998;31:8230.

[36] Supaphol P, Spruiell JE. In: Proceedings of the 218th ACS National Meeting (New Orleans, USA) PMSE Division, American Chemical Society, to appear, 1999. 